\title{
Adopt ICT among Academic Staff in Aljouf University: Using UTAUT Model
}

\section{Sani Alkhasawneh}

\author{
Faculty of education, Aljouf University Sekaka, AlJouf, The Kingdom of Saudi Arabia \\ Email: sskhasawneh@ju.edu.sa \\ Salim Alanazy (Dr) \\ Faculty of education, Aljouf University Sekaka, Aljouf, The Kingdom of Saudi Arabia \\ Email: salanazy@ju.edu.sa
}

\section{Doi:10.5901/mjss.2015.v6n1p490}

\begin{abstract}
The unified theory of acceptance and use of technology (UTAUT) has proven to be a powerful theoretical tool in the analysis of the adoption of information systems and usage behavior. Therefore, the researchers developed a survey based on the instrument established by Venkatesh, et. al. (2003) to determine the major factors contributing towards academic staff's intention to adopt ICT at Al Jouf University. Sixty academic staff members from different colleges in the Al Jouf University participated in this study. The results of the study supported the UTAUT model. However, the results showed that the UTAUT constructs did not have a significant effect on intention in the presence of interactions with gender and age.
\end{abstract}

Keywords: Unified theory of acceptance and use of technology (UTAUT); Adoption Information and Communication Technology (ICT), Saudi Arabia.

\section{Introduction}

In this century, the discussion is not about using technology or ignoring it, it is about how to adopt Information and Communication Technology (ICT) in the teaching and learning process. By definition, ICT is any communication device such as software, hardware, computer and network, etc. (Oye, A.lahad, \& Ab.Rahim, 2012). To illustrate, ICT is the application of general components of information and communication technologies to all aspects of the teaching and learning process (Lepičnik-Vodopivec \& Samec, 2012). The adoption of ICT in the teaching and learning process is divided into tools for teaching curriculum development, staff development and student learning (Leaser, 2010). Therefore, ICT is required from academic staff in order to enhance and support the teaching and learning process (Mostert \& Quinn, 2009).

The adoption of ICT in higher education institutions has increased globally (Usluel, Aşkar, \& Baş, 2008). Similarly, The Kingdom of Saudi Arabia's Ministry of Education adopted ICT into the education system, albeit later than neighboring countries (Al-Zahrani, 2012). Due to a well-developed economy, Saudi Arabia also integrated ICT into Saudi Arabia's higher education system (Alturise \& Alojaiman, 2013). The University of Al Jouf is one of the newly born universities in Saudi Arabia. Therefore, the researchers have explored the issue of ICT adoption at the University of Al Jouf.

\subsection{The Problem Statement}

The knowledge of ICT adoption improves the usability of ICT in the teaching and learning process. It gives the academicians, practitioners and policy-makers clear vision with respect to the reality of using ICT. Therefore, this study examined factors affecting the behavioral intention to use ICT among academic staff at Al Jouf University.

\subsection{Research Objective}

The purpose of the present study is to determine the major factors contributing to academic staff's intention to adopt ICT at Al Jouf University. To illustrate, this study investigated the relationships between Performance Expectancy (PE), Effort Expectancy (EE), Social Influence (SI) and Perceived Facilitating Conditions (PFC) and behavioral intention to use technology. 


\section{Literature Review}

There are many theories regarding the usability of technology. One of the well-known models related to technology acceptance models and use is the Unified Theory of Acceptance and Use of Technology (UTAUT) originally proposed by Venkatesh, Morris, Davis and Davis (2003).

Venkatesh et al. (2003) combined eight models into their Unified Theory of Acceptance and Use of Technology. The work proposed by these authors was integrated into the following theories: the Theory of Reasoned Action (TRA), the Technology Acceptance Model (TAM), the Motivational Model (MM), the Theory of Planned Behavior (TPB), an associated Theory of Planned Behavior with Technology Acceptance Model (C-TPB-TAM), the Model of PC Utilization (MPCU), the Innovation Diffusion Theory (IDT), and the Social Cognitive Theory (SCT). The UTAUT model eliminated the limitations and incorporated various strengths and useful aspects of these older models. The following figure 1 shows the UTAUT model (Venkatesh et al., 2003).

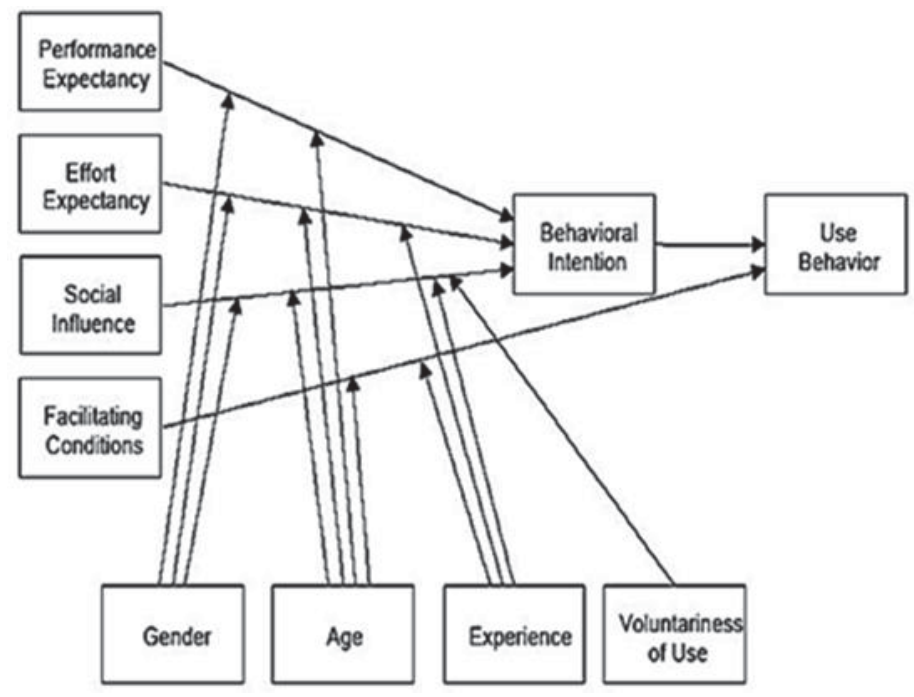

Figure 1. The Unified Theory of Acceptance and Use of Technology

Source: Venkatesh et al. (2003).

The UTAUT model showed that factors affecting behavioral intention (BI) to use technology include Performance Expectancy (PE), Effort Expectancy (EE), Social Influence (SI) and Perceived Facilitating Conditions (PFC). PE "is the degree to which an individual believes that using the system will help him or her to attain gains in performance" (Venkatesh, et al, 2003, p. 447). EE is "the degree of ease associated with the use of the system" (Venkatesh, et al, 2003, p. 450). SI is "the degree to which an individual perceived that important others believe he or she should use the new system" (Venkatesh, et al, 2003, p. 451). PFC is "the degree to which an individual believes that an organizational and technical infrastructure exists to support use of the system" (Venkatesh, et al, 2003, p. 453).

The UTAUT model has been tested in differential, dynamic and complex situations like that of a web log system (Li \& Kishore, 2006). The research investigated UTAUT across different subgroups of the population studied, based on various demographic characteristics, and proved that UTAUT demonstrates strong invariance in terms of the measurements derived from its use. The UTAUT has proven to be a powerful theoretical tool in the analysis of the adoption of information systems and usage behavior (Al-Qeisi, 2009).

\subsection{Conceptual Framework}

The current research conceptual framework depicts the research variables. The independent variable is ICT usage. The dependent variables are Performance Expectancy (PE), Effort Expectancy (EE), Social Influence (SI) and Perceived Facilitating Conditions (PFC). The moderate variables are Gender and Age. Figure 2 shows the conceptual framework. 


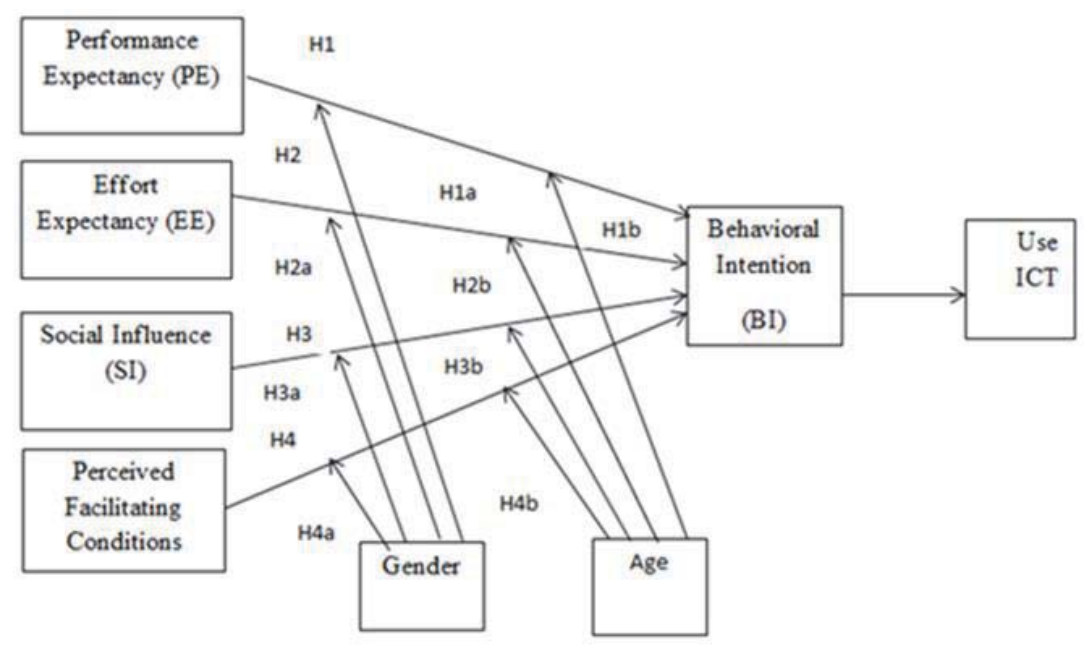

Figure 2. The Research Conceptual Framework

In the light of the conceptual framework, the present study tested the following hypotheses:

H1: Academic Staff at Al Jouf University with high performance expectancy will have high behavioral intention to use ICT.

H1a: Gender will significantly moderate the influence of performance expectancy on behavioral intentions to use ICT.

H1b: Age will significantly moderate the influence of performance expectancy on behavioral intentions to use ICT.

H2: Academic Staff at Al Jouf University with high effort expectancy will have high intention to use ICT.

H2a: Gender will significantly moderate the influence of effort expectancy on behavioral intentions to use ICT.

$\mathrm{H} 2 \mathrm{~b}$ : Age will significantly moderate the influence of effort expectancy on behavioral intentions to use ICT.

H3: Academic Staff at Al Jouf University perceiving high social influence of significant others will have high behavioral intention to use ICT.

H3a: Gender will significantly moderate the influence of social influence on behavioral intentions to use ICT.

$\mathrm{H} 3 \mathrm{~b}$ : Age will significantly moderate the influence of social influence on behavioral intentions to use ICT.

H4: Academic Staff at Al Jouf University with high facilitating conditions will have high behavioral intention to use ICT.

H4a: Gender will significantly moderate the influence of facilitating conditions on behavioral intentions to use ICT.

$\mathrm{H} 4 \mathrm{~b}$ : Age will significantly moderate the influence of facilitating conditions on behavioral intentions to use ICT.

\section{Research Methodology}

The researchers developed a survey based on the instrument established by Venkatesh, et. al. (2003). Data collection ensued from April 2014 through June 2014. The research subjects were academic staff members at Al Jouf University. Sixty academic staff members were selected from different colleges in the Al Jouf University such as health, management, science and education. In addition, $41.7 \%$ were male and $58.3 \%$ were female as shown in table 1 . Table 2 provides a summary of the participants' age, and Table 3 summarizes their reported major.

Table 1. Participant Gender $(\mathrm{n}=60)$

\begin{tabular}{|cc|c|c|}
\hline & & Frequency & Percent \\
\hline \multirow{3}{*}{ Valid } & Male & 25 & 41.7 \\
& Female & 35 & 58.3 \\
& Total & 60 & 100.0 \\
\hline
\end{tabular}


Table 2. Participant Ages $(n=60)$

\begin{tabular}{|c|c|c|c|}
\hline & & Frequency & Percent \\
\hline \multirow{5}{*}{ Valid } & less than 30 & 11 & 18.3 \\
\hline & $30-39$ & 16 & 26.7 \\
\hline & $40-49$ & 31 & 51.7 \\
\hline & $50-59$ & 2 & 3.3 \\
\hline & Total & 60 & 100.0 \\
\hline
\end{tabular}

Table 3. Reported Majors ( $n=60)$

\begin{tabular}{|c|c|c|c|}
\hline & & Frequency & Percent \\
\hline \multirow{5}{*}{ Valid } & Health & 10 & 16.7 \\
\hline & Management & 16 & 26.7 \\
\hline & Science & 22 & 36.7 \\
\hline & Education & 12 & 20.0 \\
\hline & Total & 60 & 100.0 \\
\hline
\end{tabular}

According to Lodico, Spaulding, and Voegtle (2006), reliability is the degree to which a test consistently measures whatever it is measuring. Therefore, a reliability analysis was conducted for the scales using Cronbach's Alpha. Table 4 is a summary of the scales representing the UTAUT constructs that appear to have a good degree of reliability, as each computed statistic is above .70 .

Table 4. Reliability Analysis $(\mathrm{n}=60)$

\begin{tabular}{|l|c|c|}
\hline UTAUT Construct & Cronbach's Alpha & Number of Items \\
\hline Behavioral intention & .894 & 6 \\
\hline Performance Expectancy(PE) & .905 & 6 \\
\hline Effort Expectancy (EE) & .82 & 6 \\
\hline Social Influence (SI) & .731 & 5 \\
\hline Perceived Facilitating Conditions (FC) & .722 & 5 \\
\hline
\end{tabular}

\section{Results}

The researchers conducted Pearson correlation analysis to test the relationships among the UTAUT constructs. The UTAUT model suggests a positive relationship among the UTAUT constructs (Performance Expectancy (PE), Effort Expectancy (EE), Social Influence (SI) and Perceived Facilitating Conditions (FC) and Behavioral Intention (BI).

The result showed that there is a positive relationship among the UTAUT constructs Performance Expectancy (PE), Effort Expectancy (EE), Social Influence (SI) and Perceived Facilitating Conditions (FC) and Behavioral Intention (BI) as shown in table 5 below:

\section{Table 5. Pearson correlation $n=60$}

\begin{tabular}{|l|c|c|l|}
\hline Hypotheses & $\mathrm{R}$ & $\mathrm{P}$ & Result \\
\hline $\begin{array}{l}\mathrm{H} \text { 1: Academic Staff at Al Jouf University with high PE will } \\
\text { have high BI to use ICT. }\end{array}$ & .759 & .000 & $\begin{array}{l}\text { There was a positive correlation between } \\
\text { the two variables. }\end{array}$ \\
\hline $\begin{array}{l}\mathrm{H} \text { 2: Academic Staff at Al Jouf University with high EE will } \\
\text { have high BI to use ICT. }\end{array}$ & .569 & .000 & $\begin{array}{l}\text { There was a positive correlation between } \\
\text { the two variables. }\end{array}$ \\
\hline $\begin{array}{l}\mathrm{H} \text { H: Academic Staff at Al Jouf University with high SI will } \\
\text { have high BI to use ICT. }\end{array}$ & .425 & .001 & $\begin{array}{l}\text { There was a positive correlation between } \\
\text { the two variables. }\end{array}$ \\
\hline $\begin{array}{l}\mathrm{H} 4: \text { Academic Staff at Al Jouf University with high FC will } \\
\text { have high BI to use ICT. }\end{array}$ & .315 & .016 & $\begin{array}{l}\text { There was a positive correlation between } \\
\text { the two variables. }\end{array}$ \\
\hline
\end{tabular}


Moreover, the researchers used an independent sample t-test to assess the difference in the mean scores of Male and Female. The mean scores of Performance Expectancy (PE), Effort Expectancy (EE), Social Influence (SI) and Perceived Facilitating Conditions (PFC) showed that the Male group and Female group are the same. Therefore, there are no significant mean differences between these two groups at a level of significant .05 concerning Performance Expectancy (PE), Effort Expectancy (EE), Social Influence (SI) and Perceived Facilitating Conditions (PFC).

Finally, the researchers conducted One Way ANOVA to explore the influence of age among the UTAUT constructs. Subjects were divided into four groups according to their age (Group 1: 30 and less; Group 2: 30 to 39; Group 3: 50 and above). There was no statistically significant difference at the $p<.05$ level i UTAUT constructs for the four age groups. Table 6 summarized the result.

\section{Concluding Remarks}

This study discussed academic staff members' perceptions of using ICT by applying the UTAUT model at Al- Jouf University. The results of the study supported the UTAUT model. As suggested by Venkatesh et al., we found that performance expectancy (PE), Effort Expectancy (EE), Social Influence (SI) and Perceived Facilitating Conditions (PFC) had a positive effect on intention.

Conversely, the study found that performance expectancy (PE), Effort Expectancy (EE), Social Influence (SI) and Perceived Facilitating Conditions (PFC) did not have a significant effect on intention in the presence of interactions with gender and age. These specific results correlate with the fact that technology has become a routine part of daily life utilized by all ages and genders. In our sample, most academic staff members are most likely familiar with the use of technology in their everyday lives. In today's technologically driven society, the understanding, acceptance, and use of this technology has become an essential part of modern life.

Additionally, this study identified the major factors contributing to academic staff members' intention to adopt ICT at Al Jouf University. To illustrate, this study found that Performance Expectancy (PE), Effort Expectancy (EE), Social Influence (SI) and Perceived Facilitating Conditions (PFC) had a strong effect on behavioral intention to use ICT at AI Jouf University.

\section{References}

Al-Qeisi, K. I. (2009). Analyzing the Use of UTAUT Model in Explaining an OnlineBehaviour: Internet Banking Adoption (Doctoral dissertation, Brunel University). Retrieved from http://bura.brunel.ac.uk/handle/2438/3620

Alturise, F., \& Alojaiman, B. (2013). Benefits and Challenges of Using ICT in Saudi Arabia Universities: A Literature Review. International Conference on Advanced in Computing, Engineering and Learning Technologies . 2, pp. 2-46. Abu Dhabi, UAE: ( ICACELT 2013 ).

Al-Zahrani, M. R. (2012). Self-efficacy and ICT integration into initial teacher education in Saudi Arabia: Matching policy with practice. Australasian Journal of Educational Technology, 7 (28), 1136-1151.

Leaser, D. (2010). The value of e-learning. IBM, 1-10.

Lepičnik-Vodopivec, J., \& Samec, P. (2012). Advantages and disadvantages of information-communication technology usage or fouryear-old children, and the concequences of its usage for the childrens' development. International Journal of Humanities and Social Science, 3(2), 54-58.

Li, J. P., \& Kishore, R. (2006). How Robust is the UTAUT Instrument? A Multigroup Invariance Analysis in the Context of Acceptance and Use of Online Community Weblog Systems. Proceedings of the 2006 ACM SIGMIS CPR conference on computer personnel research, 347-359.

Lodico, M. G., Spaulding, D. T., \& Voegtle, K. (2006). Methods in Educational Reseach. United States of AMERICA: Jossey-Bass.

Mostert, M., \& Quinn, L. (2009). Using ICTs in teaching and learning: Reflections on professional development of academic staff. International Journal of Education and Development using Information and Communication Technology (IJEDICT), 5(5), 72-84.

Oye, N. D., A.lahad, N., \& Ab.Rahim, N. Z. (2012). The Impact of UTAUT Model and ICT Theoretical Framework on University Academic Staff: Focus onAdamawa State University, Nigeria. International Journal of Computers \& Technology, 2(2), 102-111.

Usluel, Y. K., Aşkar, P., \& Baş, T. (2008). A structural equation model for ICT usage in higher education. Educational Technology \& Society, 11(2), 262-273.

Venkatesh, V., Morris, M. G., Davis, G. B., \& Davis, F. D. (2003). User acceptance of information technology: Towards a unified view. MIS Quarterly, 27(3), 425-478. 